\title{
A Study on the Quality of Insurance Services in Romania
}

\section{Ciprian MATIS ${ }^{\star}$}

\begin{tabular}{l}
\hline \multicolumn{1}{c}{ A R T I C L E I N F O } \\
\hline Article history: \\
Accepted March 2021 \\
Available online May 2021 \\
\hline JEL Classification \\
G22 \\
Keywords: \\
Quality of service, Client \\
expectations, Client perceptions, \\
variables, Kendall correlation \\
coefficient
\end{tabular}

1. Introduction

In the context of the internationalization of the distribution of insurance products and services, the success of the companies in this field depends first and foremost on the complexity of the modern world today, on the businesses and the risks associated with them. When we speak of efficient management in the field of insurance, this depends on the quality of the products and services offered as well as on how they are distributed. More and more electronic marketing solutions, electronic transfer of secure data, management and electronic record of insurance contracts, regulated by European Directives transposed into national legislation, are being promoted.

The clients' requirements and needs are the ones that determine the development and improvement of the services and, on the other hand, internationalization allows foran entry into the emerging markets of insurance services that differ in price and quality from those promoted by national companies.

Another factor that differentiates performance in marketing products and services is the relationship that is created between client and distributor; companies have their own strategies and policies in this regard.

Starting from the specialized literature in this field it is worth mentioning the scientific approach of Fr. Ecalle, who stated that "Each service provider has a full range of means to differentiate: of course, the quality of its performance that clients are often unable to appreciate at its fair value, the personal relationship it maintains with its clientele, the atmosphere within the unit and its geographical location"(Ecalle, p. 92).

The relationship between the volume of services and economic growth is determined not only by the income of the population but also by their awareness, information and education.

In Negoita's opinion, the improvement of the management of the services implies that managers should conduct an extensive process of analysis, which should start by pointing out the differences between the predicted objectives and the results obtained with emphasis on establishing the particularities of the management of services in the context of universal management; establishing new goals for improving and reforming all management processes in the services sector; establishing the influence that certain economic and political factors exert on the processes in the field of services; the impact of the role of human resources management in improving the management of services, etc. (Negoita p.64)

Given the development and diversification of insurance products, we cannot speak of efficient management of client management without analyzing the requirements of the code of good practice regarding how companies are run, controlled and managed - the Cadbury Report, as well as the OECD 
(Organization for Economic Co-operation and Development) Principles with respect to the management of companies (integrity, transparency, accountability and competence).

The requirements of corporate governance in insurance companies, from the perspective of affecting the rights of clients, require that management implement processes that ensure the quality of information and services throughout the client relations. When we speak about corporate governance in insurance companies, another important concept is mentioned, that of social responsibility, "The concept of social responsibility mainly targets the expectations of society with respect to business, as well as the ethical obligations of the companies towards it" (Cristache N., 2010 p.9).

Starting from the words of Cristache N. (2010), "from a qualitative point of view, of importance is the perception regarding the degree of satisfaction", correlated with the requirements of governance: transparency, integrity, responsibility and competence and social responsibility: societal expectations and the ethical obligations of companies, we can highlight four stages that must be taken into account when we refer to the management of insurance services: informing clients, analyzing the needs and needs of clients, responsibility for risk coverage through insurance contracts and assistance during the validity period of insurance contracts.

The words stated by Nistor regarding the definition of the term of service are worth mentioning "The service is an ensemble of services that the client expects depending on price, image and reputation" (Nistor, 2007 pg.18)

We cannot omit the research conducted by Williams C.A. and Heins R.M. in Management and Insurance, studies focused on the analysis of management in insurance, its development and improvement under the conditions of globalization. The mentioned works answer a series of questions regarding the principles and objectives of the management teams regarding the offer of products and services, an element of strategy in the field of business development.

The documentation for this study also took into account the Customer Satisfaction Standard issued by the British Standards Institute under the name of the British Standard Code of Practice for Customer Service $B S$ 8477. Knowing and applying the standard allows management to apply effective policies for retaining and attracting new clients, focusing on proactivity, anticipating their needs, but also promptly resolving any damages that may arise (Minculete Gh., 2013).

Important regulations that were the basis of the study are those presented by the EU Directive $97 / 2016$ regarding the organization and functioning of the insurance and reinsurance distributors and the harmonization of the national provisions in the insurance field. The directive that applies beginning with 2018 and in Romania provides measures necessary to strengthening the internal market, promoting the quality of insurance products and services.

The development of services in accordance with the needs and requirements of the clients contributes to achieving the macroeconomic balance, to the development of some sectors of activity, the efficient use of human resources.

\section{Research methodology}

To carry out the study we used as a research instrument the questionnaire addressed to 544 clients of insurance companies and insurance intermediaries, natural and legal persons. Their selection was made exhaustively, within the limits of the availability of involvement. The method of data collection was the direct administration of questionnaires as well as the indirect method, through an electronic communication format and channel. The participants were given a series of questions and the data recorded from the observation was subjected to adjustment, grouping, aggregation in order to reduce them to a reasonable number and to make them meaningful and easy to use in analysis and instrumentation.

The questionnaire aims to evaluate the qualitative factors that compete with the consumption of insurance services and which have a directly proportional relationship with the concerns regarding the management policies of the insurance companies. The questionnaire is structured in two parts and comprises a number of 22 questions about the facilities offered, the training of the employees, the quality of the services, the way of solving the damages, the personalization of the products according to the interests and needs of the clients. The first part refers to the clients' expectations regarding the quality of the services offered by the insurance industry in Romania and the second part asks the clients to classify the services of the insurance industry according to the real experience and perceptions.

From the calculation of the representativeness of the sample with the help of the Cochran formula it was found that the sample of the interviewed subjects is $100 \%$ statistically representative based on the $95 \%$ confidence interval, a c coefficient of 1.96 and accuracy of 0.05 .

Both direct observation and statistical methods were used in research. Based on the answers obtained from the respondents, we established the variables and the items related to each variable, based on which the hypotheses formulated were tested, through SPSS statistical analysis and the use of Kendall's correlation coefficient. 


\section{Validating the hypotheses with respect to the quality of services offered by insurers and intermediaries}

Based on the answers from the questionnaires, we set out to measure the degree of correlation between the real perceptions and the expectations of the clients regarding the quality of services in the insurance industry. We looked at whether the clients' real perceptions are in line with expectations, regarding: the interest and the proactive attitude towards the problems they are facing (damage); how to provide services regarding information, time, quality; preparation, confidentiality and security in product promotion; customization of products according to the needs and interests of clients; eliminating errors and malfunctions in the systems of insurers; compliance with the standards for supporting the clients' confidence in the services offered, keeping the employees of insurance companies and intermediaries.

Then, we established 22 variables and the items related to each variable, based on which we tested, through a SPSS statistical analysis, the hypotheses formulated thus.

H1(01) The quality of services offered to clients of insurance companies depends on: analyzing the requirements and needs of the clients according to the type of product, the type of clients and the type of intermediary; promotional materials and tangible facilities offered; the professionalism and competence of the employees who are involved in sales activities; timely completion of sales; the optimal conditions of the contracts; interest in resolving damages in an optimal time; confidentiality and security in the operations.

Within this analysis we established an average, $\bar{X}=\frac{\sum_{i=1}^{R} x_{i}^{\prime} \cdot N_{i}}{\sum_{i=1}^{R} N_{i}}$ (Buiga A., 2018, pg 91)of the

answers for each category, and then weplaced them in ascending order according to it, so as to see to what extent the relations of collaboration between the insurance companies, brokers and clients are determined by the newly created variables, based on the expectations of the clients.

Table 1. The quality of services offered to clients of insurance companies
\begin{tabular}{|l|c|}
\hline \multicolumn{1}{|c|}{$\begin{array}{c}\text { Determining factors for collaborative } \\
\text { relations }\end{array}$} & Average \\
\hline $\begin{array}{l}\text { Analyzing the requirements and needs of the } \\
\text { clients according to the type of product, the type of } \\
\text { client and the type of intermediary }\end{array}$ & 4.1980 \\
\hline Timely sales & 4.2271 \\
\hline $\begin{array}{l}\text { Promotional materials and the tangible facilities } \\
\text { offered }\end{array}$ & 4.3121 \\
\hline $\begin{array}{l}\text { The professionalism and competence of the } \\
\text { employees who are involved in sales activities }\end{array}$ & 4.3289 \\
\hline Unrolling of contracts in an optimal manner & 4.3396 \\
\hline $\begin{array}{l}\text { Confidentiality and safety while carrying out } \\
\text { operations }\end{array}$ & 4.4027 \\
\hline Interest in resolving damages in a timely fashion & 4.4653 \\
\hline \multicolumn{2}{|c}{ Source: Author's projection } \\
\hline
\end{tabular}

According to the table above, the quality of services offered by insurance companies and clients is determined by the following variables:

- The most important factor is the interest for the optimal resolution of the damages, which obtains an average of about 4.47 following the clients' answers;

- The second most important factor is confidentiality and security in the operations, with an average of about 4.4;

- The third factor as important in the clients' view is the optimal performance of the contracts, with an average of about 4.34;

- The least important factor in the relationships between the insurance companies, brokers and the client, according to the clients 'expectations, is the analysis of the clients' needs and needs according to the type of product, the type of client and the type of intermediary. As a result of this analysis, this factor obtained an average of about 4.2;

H2(02) Expectations of the clients regarding the quality of the services of the insurance industry depend on:the professionalism and competence of the employees who are involved in activities prior to the conclusion of contracts, the conclusion of contracts and after the conclusion of insurance policies; data 
protection mode, regardless of distribution channels; the mode of providing consultancy in choosing the insurance product according to requirements and needs; how to penetrate insurance products; avoiding unfair and abusive practices in insurance contracts; avoiding the conflict of interests in the activity of insurance distribution; implementation of a client-oriented culture.

$$
\text { Like in the case of hypothesis H1, we created an average, } \bar{X}=\frac{\sum_{i=1}^{R} x_{i}^{\prime} \cdot N_{i}}{\sum_{i=1}^{R} N_{i}} \text { for the answers for each }
$$

individual category, after which we ordered them in ascending order according to it, so as to see to what extent the expectations of the clients regarding the quality of the services of the insurance companies and the insurance brokers are determined by the newly created variables.

Table 2. Client expectations regarding the quality of services in the insurance industry

\begin{tabular}{|l|c|}
\hline \multicolumn{1}{|c|}{ Factors } & Average \\
\hline Implementation of a client-oriented culture & 4.1314 \\
\hline Data protection mode, regardless of distribution channels & 4.2030 \\
\hline $\begin{array}{l}\text { Mode of providing consultancy in choosing the insurance product } \\
\text { according to requirements and needs }\end{array}$ & 4.2338 \\
\hline $\begin{array}{l}\text { Professionalism and competence of employees in activities prior to } \\
\text { the sale, sale and after the sale of insurance policies }\end{array}$ & 4.3369 \\
\hline Avoidance of unfair and abusive practices in insurance contracts & 4.3613 \\
\hline Avoidance of conflict of interest in insurance distribution activity & 4.3960 \\
\hline Modes of penetrating insurance products & 4.4262 \\
\hline
\end{tabular}

Source: Author's projection

We observe in the table above that the most important factors on which the expectations of the clients depend on the quality of the insurance services are:

- The penetration mode of insurance products, with an average of 4.4262. Clients, on average, partially agree with this factor;

- The second most important factor is the avoidance of the conflict of interest in the insurance distribution activity with an average of 4.3960 on the LIKERT scale;

- And the least important factor, according to the expectations of the clients, is the implementation of a customer-oriented culture, with an average of about 4.1314 .

H3(03) Clients' perceptions of the quality of insurance industry services are determined by: the professionalism and competence of the employees who are involved in activities prior to the sale, sale and after the sale of insurance policies; data protection mode, regardless of distribution channels; how to provide consultancy in choosing the insurance product according to requirements and needs; how to penetrate insurance products; avoiding unfair and abusive practices in insurance contracts; avoiding the conflict of interests in the activity of insurance distribution; implementation of a client-oriented culture.

In this hypothesis we used the same analysis as in the previous two hypotheses. We made an average,

$$
\bar{X}=\frac{\sum_{i=1}^{R} x_{i}^{\prime} \cdot N_{i}}{\sum_{i=1}^{R} N_{i}} \text { of the answers for each category, and then weplaced them in ascending order according to }
$$

it, so as to see to what extent the perceptions of the clients regarding the quality of the services of the insurance companies and the insurance brokers are determined by the newly created variables.

Table 3. Perceptions of clients on the quality of insurance industry services

\begin{tabular}{|l|c|}
\hline \multicolumn{1}{|c|}{ Factor } & Average \\
\hline Penetration mode for insurance products & 3.5671 \\
\hline $\begin{array}{l}\text { Avoidance of unfair and abusive practices in insurance } \\
\text { contracts }\end{array}$ & 3.6566 \\
\hline Implementation of a client-oriented culture & 3.6605 \\
\hline Data protection mode, regardless of distribution channels & 3.7097 \\
\hline $\begin{array}{l}\text { Professionalism and competence of employees in activities } \\
\text { prior to the sale, sale and after the sale of insurance policies }\end{array}$ & 3.7604 \\
\hline
\end{tabular}




\begin{tabular}{|l|c|}
\hline \multicolumn{1}{|c|}{ Factor } & Average \\
\hline $\begin{array}{l}\text { Mode of providing consultancy in choosing the insurance } \\
\text { product according to requirements and needs }\end{array}$ & 3.9251 \\
\hline $\begin{array}{l}\text { Avoidance of conflict of interest in insurance distribution } \\
\text { activity }\end{array}$ & 3.9413 \\
\hline
\end{tabular}

Source: Author's projection

In the previous table we notice that the situation has changed with the shift from expectations to perceptions. According to the clients 'perceptions, the most important factor is the avoidance of the conflict of interest in the insurance distribution activity, with an average of about 3.94, a factor that ranks second in importance regarding the clients' expectations. We can also see that this average fell from 4,396 to about 3.94, which means that client expectations are not exactly met.

With respect to the second most important position, we have the mode of providing consultancy in choosing the insurance product according to requirements and needs, with an average of about 3,925. This factor is among the least important factors according to client expectations (5th place as importance) with an average of about 4.23 .

The least important factor, according to the perceptions of the clients, is precisely the factor that is considered the most important, according to the expectations of the clients, namely the way of penetrating the insurance products, with an average of about 3.57.

H4 (04) In the Romanian insurance industry there is a direct connection between the expectations of the clients regarding the quality of the insurance services and their perception on the quality of the services provided by the insurance companies.

We analyzed the variables from hypotheses $\mathrm{H} 2$ and $\mathrm{H} 3$ with the related items.

In this hypothesis, we have analyzed Kendall's correlation coefficient $\tau=\frac{P-Q}{P+Q}=\frac{P-Q}{\frac{n(n-1)}{2}}$ between client expectations and perceptions.

Table 4.Client expectations versus their perceptions regarding service quality

\begin{tabular}{|l|c|}
\hline Factor & Kendall correlation coefficient \\
\hline $\begin{array}{l}\text { Professionalism and competence of employees in } \\
\text { activities prior to the sale, sale and after the sale of } \\
\text { insurance policies }\end{array}$ & 0.797 \\
\hline $\begin{array}{l}\text { Data protection mode, regardless of distribution } \\
\text { channels }\end{array}$ & 0.152 \\
\hline $\begin{array}{l}\text { Mode of providing consultancy in choosing the } \\
\text { insurance product according to requirements and needs }\end{array}$ & -0.059 \\
\hline Penetration mode for insurance products & 0.304 \\
\hline $\begin{array}{l}\text { Avoidance of unfair and abusive practices in insurance } \\
\text { contracts }\end{array}$ & 0.056 \\
\hline $\begin{array}{l}\text { Avoidance of conflict of interest in insurance } \\
\text { distribution activity }\end{array}$ & 0.083 \\
\hline Implementation of a client-oriented culture & -0.053 \\
\hline
\end{tabular}

Source: Author's projection

According to the table above, we have a strong direct link between the expectations and perceptions of the clients with respect to the professionalism and competence of the employees who are involved in activities prior to, during and after the sale of insurance policies. In addition, we have a direct but weak link between the expectations and perceptions of the clients regarding the penetration mode of the insurance products, but also in the case of the data protection mode, regardless of the distribution channels.

In the case of the other variables, we have no significant links between client expectations and perceptions.

\section{Conclusions}

The factorial analysis of the data sought to validate the assumptions made regarding the quality of services in the insurance industry. The results of the correlations between the variables grouped to prove the four hypotheses are as follows:

- The quality of the services offered to the clients by the insurance companies is determined by the interest for the optimal resolution of the damage claims, the confidentiality and security in the execution of the operations, the optimal conditions of the contracts and the analysis of the clients' desires and needs; 
- The most important factors on which the expectations of the clients depend, with respect to the quality of the insurance services, are: the penetration mode of the insurance products, avoiding conflicts of interests in the activity of insurance distribution, and implementing a customer-oriented culture;

- According to the perceptions of the clients, the most important factor on which the quality of services depends is the avoidance of conflicts of interests in the activity of insurance distribution, the mode of consulting in choosing the insurance product according to requirements and needs, the penetration of insurance products;

- The results of the research demonstrate the existence of a strong direct connection between the expectations and perceptions of the clients regarding the quality of the services with respect to the professionalism and competence of the employees who are involved in activities prior to, during and after the sale of insurance policies. In addition, we have a direct but weak link between the expectations and perceptions of the clients, regarding the penetration of insurance products, but also in the case of the data protection mode, regardless of the distribution channels;

- According to client perceptions, insurance companies and brokers have as their strengths for improving services, using negotiation strategies and techniques in client relations, managing client relationships, their ability to close sales at the right time, and arguing client objections with which they interact;

- We can conclude that the empirical research regarding the connection between the quality of services and influencing factors such as: professionalism and competence of the employees, the mode of data protection regardless of the distribution channels, the mode of consulting in choosing the insurance product according to requirements and needs, the penetration mode for insurance products, avoiding incorrect and abusive practices in insurance contracts, avoiding conflict of interests in insurance distribution activity, implementing a customer-oriented culture has shown that in the Romanian insurance industry there is a direct connection between the quality of services and the factors mentioned. This aspect directly influences the distribution of insurance products and services and implicitly the performance of insurance companies and intermediaries.

\section{References}

1. Asumadu-Sarkodie, S.; Owusu, P.A. (2016), The casual nexus between child mortality rate, fertility rate, GDP, household final consumption expenditure, and food production index. Cogent Econ. Financ.

2. Buiga, A., Cristian, D., Lazăr, D.,Brendea, G., Litan,C., Mare, C., (2018), StatisticăDescriptivă, EdituraNapoca Star, Cluj-Napoca;

3. Bhargava, A.; Jamison, D.T.; Lau, L.J.; Murray, C.J. (2001), Modeling the effects of health on economic growth. J. Health Econ./20, 423440 .

4. $\quad$ Cristache N., Susanu O., (2010), Responsabilitate sociala corporatista, Editura University press, Galati;

5. Dicu, R.M.; Toma, C.; Aevoae, G.M.; Mardiros, D.N. (2019), The Influence of Deal Value's Determinants in Mergers and Acquisitions with Community Dimension: Some Empirical Evidence from the European Union. Transform. Bus. Econ.no, 18, 42-59.

6. Ecalle, Fr., (1989), L economie des services, PUF, Paris;

7. Minculete, G. (2013), Issues Regarding Electronic Commerce And E-Marketing, International Scientific Conference "Strategies XXI", suppl. Technologies - military applications, simulations and..; Bucharest Vol. 2, : 26-32. Bucharest: "Carol I" National Defence University.

8. Martines, J.; Paul, V.K.; Bhutta, Z.A.; Koblinsky, M.; Soucat, A.; Walker, N. Lancet, (2005), Neonatal Survival Steering Team. Neonatal survival: A call for action. Lancet, 365, 1189-1197.

Negoita, A.,(1977), Stiinta administratiei, Editura Didactica și Pedagogică, Bucuresti;

Nistor, L.R., (2007), De la calitate la managementulcalitățiitotale, Cluj-Napoca, Editura Alma Mater, p. 18;

Williams C.A., Heins R.M., (1985) Management and Insurance, 5th edition, McGraw-Hill Insurance Series, New York;

British Standard Code of Practice for Customer Service BS 8477

Cadbury Report;

Organization for Economic Co-operation and Development (OECD), EU Commission. GDP and beyond: Measuring Progress in a Changing World; COM: (2009) 43Available online:https://ec.europa.eu/eurostat/cros/content/gdp-and-beyond-measuringprogress-changing-world_en (accessed on 22 March 2021) 